\title{
sciendo
}

Int. J. of Applied Mechanics and Engineering, 2021, vol.26, No.4, pp.51-62

DOI: 10.2478/ijame-2021-0049

\section{REDUCED EQUATIONS OF SLOPE-DEFLECTION METHOD IN STRUCTURAL ANALYSIS}

\author{
Muhammed Abbas HUSAIN* and Zahraa Hameed HASAN \\ Department of Civil Engineering, College of Engineering, University of Samarra, IRAQ \\ E-mail:mhmdabbas@uosamarra.edu.iq
}

\begin{abstract}
This paper presents an update of the slope-deflection method, which is used in the analysis of statically indeterminate structures. In this study, new reduced equations are presented based on including both the effects of the member rotations and the fixed end moments in one term, rather than two terms, in order to simplify the application of the slope-deflection method. The reduced equations are developed, then three numerical examples with comprehensive cases of beams are solved by applying both the original and the proposed reduced equations. The analysis outputs indicated that the reduced equations are applicable for all cases that can be analyzed by the slope-deflection method, and give identical results compared with the original equations. It is found that the reduced equations require less computations when the structure has no support settlement, compared with the original equations, whereas the computations are approximately similar when the structure has a support settlement.
\end{abstract}

Key words: indeterminate structures, slope-deflection, structural analysis, classical methods, reduced equations.

\section{Introduction}

The analysis methods of statically indeterminate structures can be classified generally into two categories; the force (or flexibility) methods, and the displacement (or stiffness) methods [1-3]. The slopedeflection is one of the displacement methods [2-6], and it is based on the principle of superposition of the effects of the joint displacements to find the forces in the structures [1].

Slope-deflection method was introduced by George A. Maney in 1915, and it is used to analyze statically indeterminate beams and frames $[3,5]$. The method relates the moments at the ends of the members to their slopes and deflections [4, 7-9].

Generally, the analysis by using the slope-deflection method is achieved by applying a slope-deflection equation at each end (near and far ends) of the member, then the equilibrium equations are applied for the joints that are free to rotate, and finally by solving a system of simultaneous equations [3]. In some cases (when the span of the beam or frame is supported by a pin or a roller at its end), only one slope-deflection (modified slope-deflection) equation can be used for the member [2, 3].

The main advantages of using the slope-deflection method are the ease of programming and the applicability of a wide range of indeterminate structures [2]. Also, the method significantly contributes to developing the modern stiffness matrix method, and it is enabling the analyst to easier sketch the deformed shapes of the structures [5].

The slope-deflection method was basically developed to analyze the statically indeterminate twodimensional beams and frames. However, this method has been used later by many researchers to analyze other cases of structures. Yoshida [10] used the slope-deflection method to analyze the statically indeterminate space frames. The slope-deflection equations with the torsional equation of the member section were used for dealing with the three-dimensional frames. Backer et al. [11] adopted an analytical method to analyze the orthotropic plated bridge decks. The internal forces in the bridge deck section were calculated by applying the slope-deflection equations. Dario [12] studied the stability analysis of Timoshenko beam-column connections

\footnotetext{
${ }^{*}$ To whom correspondence should be addressed.
} 
in the structures. A set of slope-deflection equations was developed for the beam-columns with symmetrical semi-rigid connections, by considering a combination of the shear, moment, and second-order axial deformation effects. Riahi et al. [13] investigated the determination of buckling load for the tapered columns by using the slope-deflection method. Based on the varying moment of inertia for the non-prismatic columns, slope-deflection equations were developed to compute the critical buckling loads for such columns.

The purpose of the current study is to present reduced forms for the slope-deflection equations in order to simplify their applications as well as to reduce the computational efforts and the time-consuming analysis process of statically indeterminate structures. The proposed equations contribute to updating the classical slope-deflection method since this method provides the basic fundamentals and concepts in the field of structural analysis, in addition to it is still used in many applications.

\section{Slope-deflection equations}

There are two main forms of slope-deflection equations; basic and modified equations [2,3]. The following subsections describe briefly each of these equations.

\subsection{Basic slope-deflection equations}

For a typical member $A B$ shown in Figure 1:

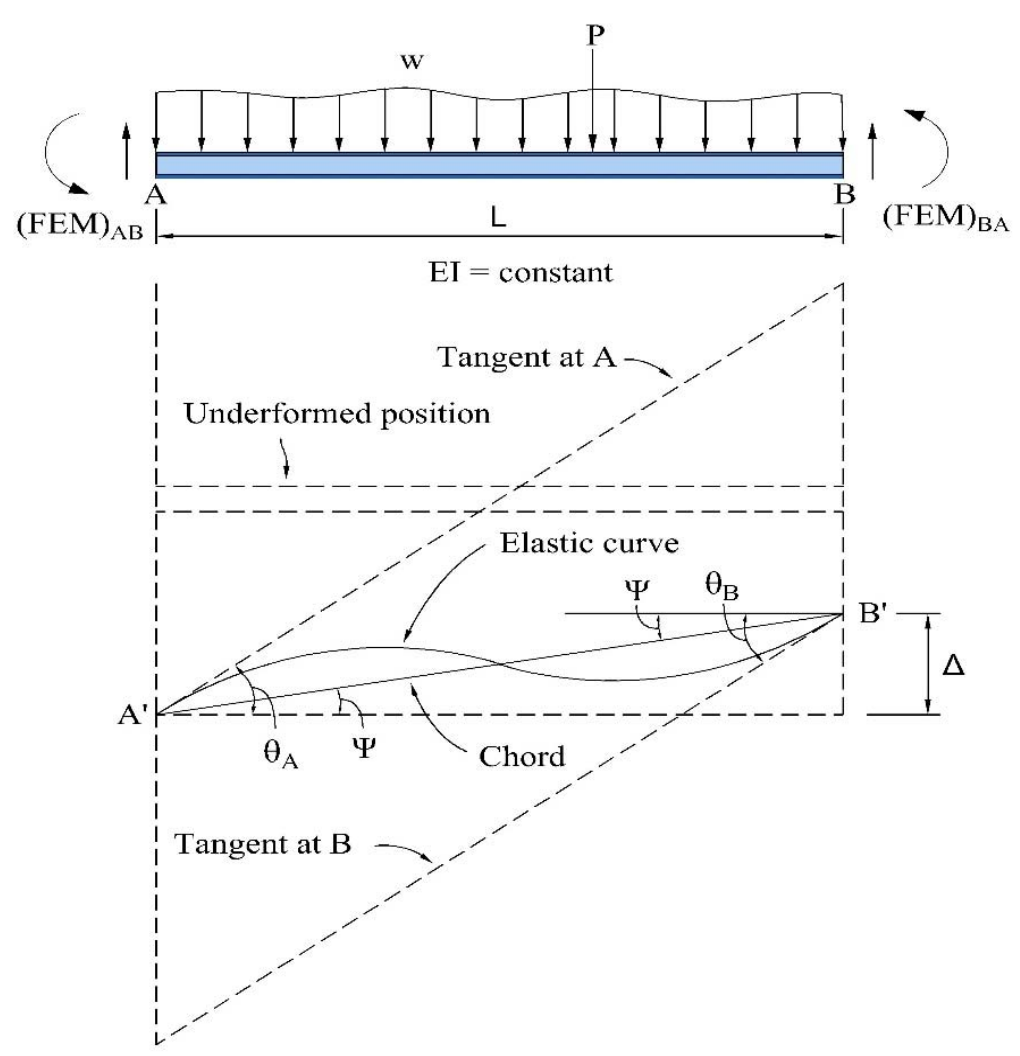

Fig.1. Typical beam member.

If the ends $A$ and $B$ are considered to be "near" and "far" ends, and denoted by the subscripts " $N$ " and " $F$ " respectively, then the basic slope-deflection equation is $[2,5]$ :

$$
M_{N F}=2 E k\left(2 \theta_{N}+\theta_{F}-3 \psi\right)+F E M_{N F}
$$


where $M_{N F}$ is internal moment at the near end; $E$ - modulus of elasticity of beam material; $K$ - member stiffness, equals $I / L ; I$ - moment of inertia of the section about the neutral axis; $L$ - span length; $\theta_{N}-$ the slope at the near end, $\theta_{F}$ - the slope at the far end; $\psi$ - member rotation, equals $\Delta / L, \Delta$-relative vertical displacement between the two ends; $F E M_{N F}$ - fixed end moment at the near end caused by the external loads. For the far end, the basic slope-deflection becomes:

$$
M_{F N}=2 E k\left(2 \theta_{F}+\theta_{N}-3 \psi\right)+F E M_{F N} .
$$

Equation (2.2) is similar to Eq.(2.1), but the difference is that the subscripts $N$ and $F$ are switched.

\subsection{Modified slope-deflection equations}

When the span of a beam or frame is supported at its far end by a pin or a roller, like the support $B$ in Fig.2., provided no external moment is applied at this end, the basic slope-deflection equation can be modified to the following slope-deflection equation $[2,5]$ :

$$
M_{N F}=3 E k\left(\theta_{N}-\psi\right)+F E M_{N F}
$$

This equation is applied only for the near end since the pinned far end has no internal moment, but it becomes not applicable when the pinned or roller end of the span is subjected to an external moment. However, an improvement was presented by Husain [14] to make it applicable by adding the value of the carry over moment, that developed at the fixed end due to the external moment, as a new term to the right side of the modified slope-deflection equation.

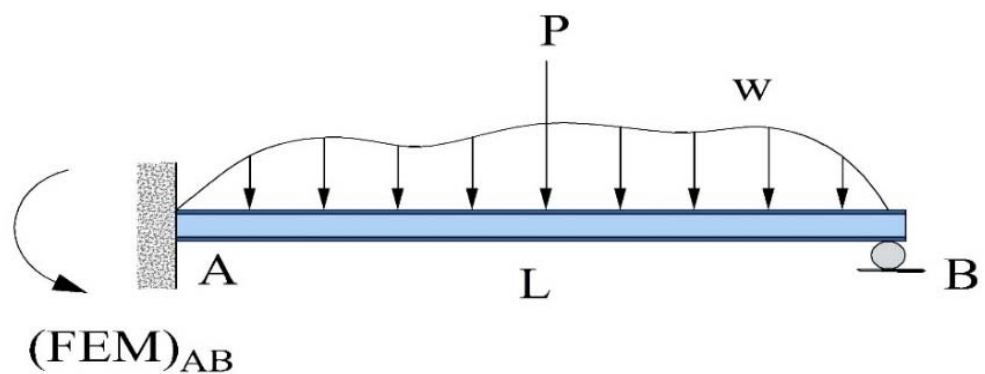

Fig.2. Typical pin end span.

\section{Formulation of the reduced equations}

The member end moments obtained from the slope-deflection equations represent the summation of three terms caused by each of the rotations of the joints $\left(\theta_{N}\right.$ and $\left.\theta_{F}\right)$, rotations of the members $(\psi)$, and the fixed end moments (FEMs) [5].

The fixed end moments in these equations are the moments developed due to external loading only, while the effect of the relative end displacement (or support settlement) is considered in the term of the member rotation $\psi$, which represents the displacement $\Delta$ for a given member length $(\psi=\Delta / L)$.

The effect of support settlement can also be considered by means of fixed end moments rather than the rotation $\psi$ because the fixed end moments are also developed due to the relative end displacement $\Delta$ as it will be described in this section. 
When the member is subjected only to a relative end displacement $(\Delta)$ as shown in Fig.3., the fixed end moments developed can be determined from the preceding basic slope-deflection equations, Eq.(2.1) and Eq.(2.2), as follows.

Since the relative displacement $\Delta$ is the only effect considered in this case, then the values of other displacements $\theta_{A}$ and $\theta_{B}$ are zeros, also since no external loads are applied, then the fixed end moments due to external loads (FEMS) are also zeros. Thus, by substituting these zero values into Eq.(2.1) at the end $A$ we get:

$$
M_{A B}=-2 E k(3 \psi)
$$

By substituting the values of $(k=I / L)$ and $(\psi=\Delta / L)$, the above equation gives:

$$
M_{A B}=-6 E I \Delta / L^{2}
$$

This value of $M_{A B}$ represents the fixed end moment at the end $A$ due to the relative displacement $\Delta$. Therefore, Eq.(3.2) can be expressed as:

$$
F E M_{A B}=-6 E I \Delta / L^{2}
$$

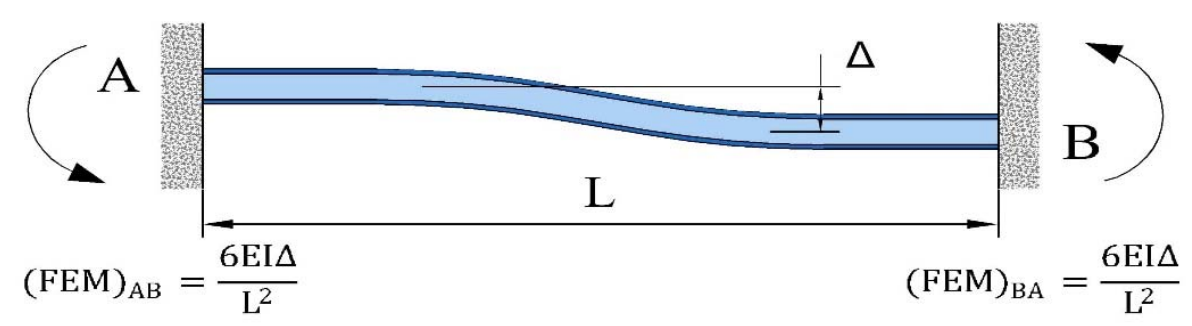

Fig.3. Fixed end moments due to support settlement.

By using the same procedure that was applied at the end $A$, the fixed end moment at the end $B$ can be obtained by applying Eq.(2.2) to get:

$$
F E M_{B A}=-6 E I \Delta / L^{2} .
$$

These values of the fixed end moments at both ends $A$ and $B$ are shown in Fig.3. The negative sign indicates that the direction of the moment is counterclockwise (based on assuming the clockwise rotation of the member to be the positive direction).

The values of FEMs in Eq.(3.3) and Eq.(3.4) are also listed in the tables of FEMs presented in many references of "structural analysis" [2,3]. These tables give the values of FEMs for the most common loading cases of beams and the cases of support settlement as well.

Based on the values of the fixed end moments obtained in Eq.(3.3) and Eq.(3.4), cancelling of the term of the member rotation $\psi$ from the slope-deflection equation and considering its effect in the term of fixed end moment will reduce the slope-deflection equation to a new simpler form.

For example, if a given member (e.g., the member in Fig.1.) is subjected only to a support settlement $\Delta$, then by using Eq.(2.1) and expanding it we get: 


$$
M_{N F}=4 E k \theta_{N}+2 E k \theta_{F}-6 E K \psi+F E M_{N F} .
$$

Since no external loading was applied on the member, then the values of fixed end moments are zeros $(F E M=0)$ and Eq.(3.5) becomes:

$$
M_{N F}=4 E k \theta_{N}+2 E k \theta_{F}-6 E k \psi .
$$

By substituting the values of $(k=I / L)$ and $(\psi=\Delta / L)$, the above equation gives:

$$
M_{N F}=2 E k\left(2 \theta_{N}+\theta_{F}\right)-6 E I \Delta / L^{2} .
$$

Now, coming back to Eq.(2.1), if the term of $\psi$ is cancelled, we get:

$$
M_{N F}=2 E k\left(2 \theta_{N}+\theta_{F}\right)+F E M_{N F} .
$$

Substituting $F E M_{N F}$ due to support settlement obtained from Eq.(3.3):

$$
M_{N F}=2 E k\left(2 \theta_{N}+\theta_{F}\right)-6 E I \Delta / L^{2} .
$$

It can be clearly noticed that the member end moments calculated from Eq.(3.7) and Eq.(3.9) are completely identical. Thus, it can be concluded that cancelling the term of $\psi$ and considering its effect in the term of FEM gives the same result of the member end moments.

Similarly, by following the same procedure used for Eq.(2.1), cancelling the terms of $\psi$ from the other slope-deflection equations, Eq.(2.2) and Eq.(2.3) give new reduced forms identical with the original forms. The original equations and the proposed reduced equations of the slope-deflection method are summarized in Table1.

The reduced equations proposed in this study are applicable for all cases of beams and frames that can be analyzed by using the original equations of the slope-deflection method. When there is no support settlement $(\psi=0)$, the reduced equations have already cancelled the term of the member rotation $\psi$, while when the support settlement exists $(\psi \neq 0)$, the effect of the member rotation $\psi$ is considered as an additional moment to the fixed end moment term.

Table 1. Original and reduced equations of slope-deflection method.

\begin{tabular}{|c|c|c|}
\hline $\begin{array}{c}\text { Equation } \\
\text { Number }\end{array}$ & Original equations & Reduced equations \\
\hline 1 & $M_{N F}=2 E k\left(2 \theta_{N}+\theta_{F}-3 \psi\right)+F E M_{N F}$ & $M_{N F}=2 E k\left(2 \theta_{N}+\theta_{F}\right)+F E M_{N F}$ \\
\hline 2 & $M_{F N}=2 E k\left(2 \theta_{F}+\theta_{N}-3 \psi\right)+F E M_{F N}$ & $M_{F N}=2 E k\left(2 \theta_{F}+\theta_{N}\right)+F E M_{F N}$ \\
\hline 3 & $M_{N F}=3 E k\left(\theta_{N}-\psi\right)+F E M_{N F}$ & $M_{N F}=3 E k \theta_{N}+F E M_{N F}$ \\
\hline
\end{tabular}

\section{Numerical examples and discussion}

The following three examples illustrate the differences in applying the analysis procedure by using the original equations and the proposed reduced equations of the slope-deflection method. These three examples 
represent comprehensive cases of beam members since they involve various combinations of the effects that can be applied on the members in practice. For the analysis of frames, since the procedure of using the slopedeflection equations for the frames is identical to those for the beams, and to avoid presenting long solutions for the frame structures in this work, only the examples of the beams are presented. These examples are representative cases to show how to use the reduced equations for both the beams and frames. In each of the three examples the negative sign of the rotations and the moments indicate that the rotational direction is counterclockwise.

Example 1: This example is presented by Hibbeler [2], it is a statically indeterminate continuous beam with fixed supports at two ends and interior roller as shown in Fig.4. In this example it is required to compute the member end moments of the beam under the effect of loadings with no support settlements. The details of procedure and results of applying both the original and the reduced slope-deflection equations are summarized in Table 2.

Table 2. Steps of the solutions and the results of example 1.

\begin{tabular}{|c|c|c|}
\hline Steps & Original equations & Reduced equations \\
\hline$F E M_{A B}$ & 0 & 0 \\
\hline$F E M_{B A}$ & 0 & 0 \\
\hline$F E M_{B C}$ & $-w l^{2} / 30=-7.2 \mathrm{kNm}$ & $-w l^{2} / 30=-7.2 \mathrm{kNm}$ \\
\hline$F E M_{C B}$ & $w l^{2} / 20=10.8 \mathrm{kNm}$ & $w l^{2} / 20=10.8 \mathrm{kNm}$ \\
\hline$\theta_{A}$ & 0 & 0 \\
\hline$\theta_{B}$ & exists & exists \\
\hline$\theta_{c}$ & 0 & 0 \\
\hline$\Psi_{A B}$ & 0 & $N / A$ \\
\hline$\Psi_{B C}$ & 0 & $N / A$ \\
\hline$E I$ & constant & constant \\
\hline \multirow{4}{*}{$\begin{array}{c}\text { Slope- } \\
\text { deflection } \\
\text { equations }\end{array}$} & $M_{A B}=2 E k\left(2 \theta_{A}+\theta_{B}-3 \psi\right)+F E M_{A B}$ & $M_{A B}=2 E k\left(2 \theta_{A}+\theta_{B}\right)+F E M_{A B}$ \\
\hline & $M_{B A}=2 E k\left(2 \theta_{B}+\theta_{A}-3 \psi\right)+F E M_{B A}$ & $M_{B A}=2 E k\left(2 \theta_{B}+\theta_{A}\right)+F E M_{B A}$ \\
\hline & $M_{B C}=2 E k\left(2 \theta_{B}+\theta_{C}-3 \psi\right)+F E M_{B C}$ & $M_{B C}=2 E k\left(2 \theta_{B}+\theta_{C}\right)+F E M_{B C}$ \\
\hline & $M_{C B}=2 E k\left(2 \theta_{C}+\theta_{B}-3 \psi\right)+F E M_{C B}$ & $M_{C B}=2 E k\left(2 \theta_{C}+\theta_{B}\right)+F E M_{C B}$ \\
\hline $\begin{array}{l}\text { Equilibrium } \\
\text { Equation }\end{array}$ & $M_{B A}+M_{B C}=0$ & $M_{B A}+M_{B C}=0$ \\
\hline $\begin{array}{c}\text { Solving for } \\
\theta_{B}\end{array}$ & $\theta_{B}=6.17 / E I$ & $\theta_{B}=6.17 / E I$ \\
\hline Results & Original equations & Reduced equations \\
\hline$M_{A B}$ & $1.54 \mathrm{kNm}$ & $1.54 \mathrm{kNm}$ \\
\hline$M_{B A}$ & $3.09 \mathrm{kNm}$ & $3.09 \mathrm{kNm}$ \\
\hline$M_{B C}$ & $-3.09 \mathrm{kNm}$ & $-3.09 \mathrm{kNm}$ \\
\hline$M_{C B}$ & $12.86 \mathrm{kNm}$ & $12.86 \mathrm{kNm}$ \\
\hline
\end{tabular}

The beam in example 1 has two spans $(A B$ and $B C)$ and only one degree of freedom at the joint $B$ (the rotation $\left.\theta_{B}\right)$, therefore, it was required to apply two slope-deflection equations for each span and one equilibrium equation at the joint $B$. The fixed end moments due to external loading are only available for the span $B C$ since the span $A B$ is free of external loading. The basic slope-deflection equations, Eq.(2.1) and Eq.(2.2), are applied 
when using the original forms, while the corresponding equations, which are presented in Table 1, are applied when using the proposed reduced forms.

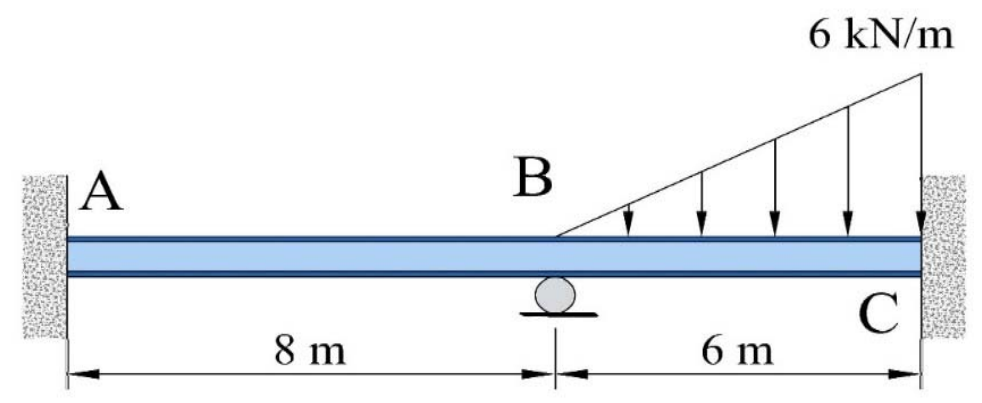

Fig.4. The beam in example 1.

The beam in this example represents the most common case for the beams in practice because it has no support settlement. Since there is no support settlement along the beam, then the values of $\psi$ in the original slope-deflection equations are all equal to zeros, while the reduced slope-deflection equations are already not including the rotation $\psi$. Therefore, it can be clearly noticed that the results are identical for both methods because the values of the variables in both methods are identical. This example shows that when there are no relative displacements (support settlements) at the joints of the members in the structures, which is a common case, the analysis by using the reduced forms is easier and shorter than that using the original forms. This can be simply evidenced by realizing that the analyst has to use a longer formula and to substitute $(\psi=0)$, whereas working with reduced forms is easier since the term $3 \psi$ does not exist in these forms.

Example 2: This example is presented by Ranzi and Gilbert [15], it is a continuous statically indeterminate beam as shown in Fig.5. In this example, it is required to analyze the beam due to support settlement of $60 \mathrm{~mm}$ downward at joint $B$. The stiffness $E I$ is given as $12000 \mathrm{kNm}^{2}$.

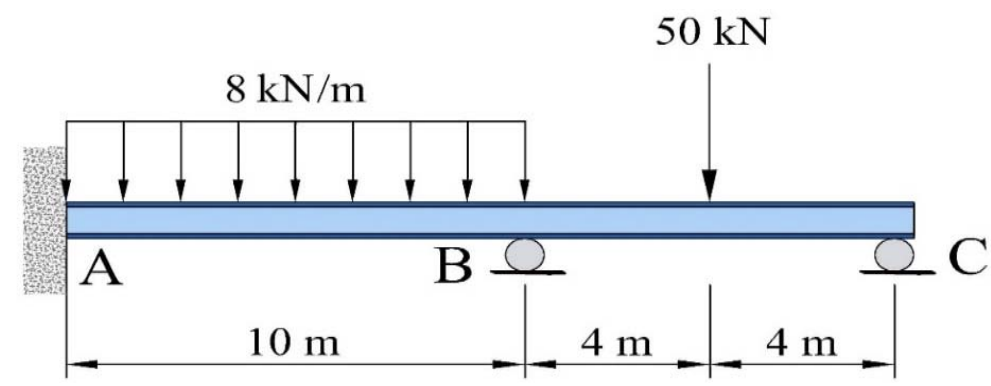

Fig.5. The beam in example 2.

The beam in example 2 has two spans $(A B$ and $B C)$ and two degrees of freedom at the joints $B$ and $C$ (the rotations $\theta_{B}$ and $\theta_{C}$ ) but the rotation at $C$ is not required in the solution because the span $B C$ has a roller at its end $C$, hence the modified slope-deflection equation, Eq.(2.3), as well as its corresponding reduced form in Table 1 are applied at the span $B C$ only. On the other hand, the basic slope-deflection equations, Eq.(2.1) and Eq.(2.2), and their corresponding reduced equations in Table 1 are used for the span $A B$.

In this example, it is required to analyze the beam under the effect of support settlement at $B$ only (the effects of the external loads were not considered by Ranzi and Gilbert [10] in order to show the net effect of the support settlement). 
This example describes clearly the difference in applying the reduced equations when the member has a relative displacement (support settlement). It can be clearly seen from Table 3 that the effect of the support settlement is considered by substituting the values of $\psi$ in the original slope-deflection equations, while the effect of the support settlement is considered as fixed end moments in the reduced slope-deflection equations. On the other hand, the FEMS for the original equations are substituted as zero values since the fixed end moments in these equations are the moments developed due to external loading only, whereas the FEMs for the reduced equations have specific values due to the included effects of the support settlement. Two values of FEM are used in the reduced slope-deflection equations ( $6 E I \Delta / L 2$ and $3 E I \Delta / L 2)$ which represent the fixed end moments due to support settlement for the fixed-fixed member (member $A B$ ) and for the fixed-pinned member (member $B C$ ) respectively. Although there are differences in the values of the fixed end moments between the original and the reduced equations, the analysis results are completely identical because the effects of the FEMs in the reduced equations are equivalent to the effects of the member rotations $\psi_{s}$ in the original equations as evidenced by the equations in the previous section.

Table 3. Steps of the solutions and the results of example 2.

\begin{tabular}{|c|c|c|}
\hline Steps & Original form & Reduced form \\
\hline$F E M_{A B}$ & 0 & $-6 E I \Delta / L^{2}=-43.2 \mathrm{kNm}$ \\
\hline$F E M_{B A}$ & 0 & $-6 E I \Delta / L^{2}=-43.2 \mathrm{kNm}$ \\
\hline$F E M_{B C}$ & 0 & $3 E I \Delta / L^{2}=33.75 \mathrm{kNm}$ \\
\hline$\theta_{A}$ & 0 & 0 \\
\hline$\theta_{B}$ & exists & exists \\
\hline$\theta_{c}$ & Not required & Not required \\
\hline$\Psi_{A B}$ & $0.06 / 10$ & $N / A$ \\
\hline$\Psi_{B C}$ & $-0.06 / 8$ & $12000 \mathrm{kNm}$ \\
\hline EI & $12000 \mathrm{kNm}$ & $M_{A B}=2 E k\left(2 \theta_{A}+\theta_{B}\right)+F E M_{A B}$ \\
\hline \multirow{2}{*}{$\begin{array}{c}\text { Slope- } \\
\text { deflection } \\
\text { equations }\end{array}$} & $M_{A B}=2 E k\left(2 \theta_{A}+\theta_{B}-3 \psi\right)+F E M_{A B}$ & $M_{B A}=2 E k\left(2 \theta_{B}+\theta_{A}\right)+F E M_{B A}$ \\
\cline { 2 - 3 } & $M_{B C}=3 E k\left(\theta_{B}-\psi\right)+F E M_{B C}$ & $M_{B C}=3 E k \theta_{B}+F E M_{B C}$ \\
\hline $\begin{array}{c}\text { Equilibrium } \\
\text { Equation }\end{array}$ & $M_{B A}+M_{B C}=0$ & $M_{B A}+M_{B C}=0$ \\
\hline $\begin{array}{c}\text { Solvingfor } \\
\theta_{B}\end{array}$ & $\theta_{B}=0.001032$ & $\theta_{B}=0.001032$ \\
\hline $\begin{array}{c}\text { Results } \\
M_{A B}\end{array}$ & $-48.25 \mathrm{kNm}$ & Reduced equations \\
\hline$M_{B A}$ & 0 & $-40.72 \mathrm{kNm}$ \\
\hline$M_{B C}$ & Original equations & $-38.25 \mathrm{kNm}$ \\
\hline$M_{C B}$ & $-40.72 \mathrm{kNm}$ & 0 \\
\hline
\end{tabular}

Example 3: This example is presented by Kassimali [3], it is a continuous statically indeterminate beam as shown in Fig.6. In this example, it is required to analyze the beam due to a combination of external loading and support settlements of $15.875 \mathrm{~mm}$ at $B, 38.1 \mathrm{~mm}$. at $C$, and $19.05 \mathrm{~mm}$ at $D$. The stiffness $E I$ of the beam is given as $649148.64 \mathrm{kNm}^{2}$. This example is presented by Kassimali [3] in FPS system units, and the units 
are converted in this study to be in SI units. This example shows the case of the beam when it is subjected to a combination of external loading and support settlement.

Table 4. Steps of the solutions and the results of example 3.

\begin{tabular}{|c|c|c|}
\hline Steps & Original form & Reduced form \\
\hline$F E M_{A B}$ & 0 & 0 \\
\hline$F E M_{B A}$ & $w l^{2} / 8=305.06 \mathrm{kNm}$ & $w l^{2} / 8-3 E I \Delta / L^{2}=-64.69 \mathrm{kNm}$ \\
\hline$F E M_{B C}$ & $-w l^{2} / 12=-203.37 \mathrm{kNm}$ & $-w l^{2} / 12-6 E I \Delta / L^{2}=-1238.67 \mathrm{kNm}$ \\
\hline$F E M_{C B}$ & $w l^{2} / 12=203.37 \mathrm{kNm}$ & $w l^{2} / 12-6 E I \Delta / L^{2}=-831.93 \mathrm{kNm}$ \\
\hline$F E M_{C D}$ & $-w l^{2} / 8=-305.06 k N m$ & $-w l^{2} / 8+3 E I \Delta / L^{2}=138.64 k N m$ \\
\hline$F E M_{D C}$ & 0 & 0 \\
\hline$\theta_{A}$ & exists & exists \\
\hline$\theta_{B}$ & exists & exists \\
\hline$\theta_{c}$ & exists & exists \\
\hline$\theta_{D}$ & exists & exists \\
\hline$\Psi_{A B}$ & 0.00174 & $N / A$ \\
\hline$\Psi_{B C}$ & 0.00243 & $N / A$ \\
\hline$\Psi_{C D}$ & -0.00208 & $N / A$ \\
\hline$E I$ & $649148.64 \mathrm{kNm}^{2}$ & $649148.64 \mathrm{kNm}^{2}$ \\
\hline \multirow{4}{*}{$\begin{array}{c}\text { Slope- } \\
\text { Deflection } \\
\text { Equations }\end{array}$} & $M_{B A}=3 E k\left(\theta_{B}-\psi\right)+F E M_{B A}$ & $M_{B A}=3 E k \theta_{B}+F E M_{B A}$ \\
\hline & $M_{B C}=2 E k\left(2 \theta_{B}+\theta_{C}-3 \psi\right)+F E M_{B C}$ & $M_{B C}=2 E k\left(2 \theta_{B}+\theta_{C}\right)+F E M_{B C}$ \\
\hline & $M_{C B}=2 E k\left(2 \theta_{C}+\theta_{B}-3 \psi\right)+F E M_{C B}$ & $M_{C B}=2 E k\left(2 \theta_{C}+\theta_{B}\right)+F E M_{C B}$ \\
\hline & $M_{C D}=3 E k\left(\theta_{C}-\psi\right)+F E M_{C D}$ & $M_{C D}=3 E k \theta_{C}+F E M_{C D}$ \\
\hline \multirow{2}{*}{$\begin{array}{c}\text { Equilibrium } \\
\text { Equations }\end{array}$} & $M_{B A}+M_{B C}=0$ & $M_{B A}+M_{B C}=0$ \\
\hline & $M_{C B}+M_{C D}=0$ & $M_{C B}+M_{C D}=0$ \\
\hline \multirow{2}{*}{$\begin{array}{l}\text { Solving for } \\
\theta_{B} \text { and } \theta_{C}\end{array}$} & $\theta_{B}=0.002421860$ & $\theta_{B}=0.002421860$ \\
\hline & $\theta_{C}=0.000703152$ & $\theta_{C}=0.000703152$ \\
\hline Results & Original equations & Reduced equations \\
\hline$M_{A B}$ & 0 & 0 \\
\hline$M_{B A}$ & $451.1 \mathrm{kNm}$ & $451.1 \mathrm{kNm}$ \\
\hline$M_{B C}$ & $-451.1 \mathrm{kNm}$ & $-451.1 \mathrm{kNm}$ \\
\hline$M_{C B}$ & $-288.4 \mathrm{kNm}$ & $-288.4 \mathrm{kNm}$ \\
\hline$M_{C D}$ & $288.4 \mathrm{kNm}$ & $288.4 \mathrm{kNm}$ \\
\hline$M_{D C}$ & 0 & 0 \\
\hline
\end{tabular}

The beam in example 3 has three spans $(A B, B C$, and $C D)$ and four degrees of freedom at the joints $A$ through $D$ (the rotations $\theta_{A}, \theta_{B}, \theta_{C}$ and $\theta_{D}$ ), but the rotations at $A$ and $D$ are not required in the solution because the end spans $A B$ are pinned and $C D$ has roller ends, hence the modified slope-deflection equation, Eq.(2.3), as well as its corresponding reduced form in Table 1 are applied at the spans $A B$ and $C D$. On the other hand, the basic slope-deflection equations, Eq.(2.1) and Eq.(2.2), and their corresponding reduced equations which are presented in Table 1 are used for the span $B C$. 


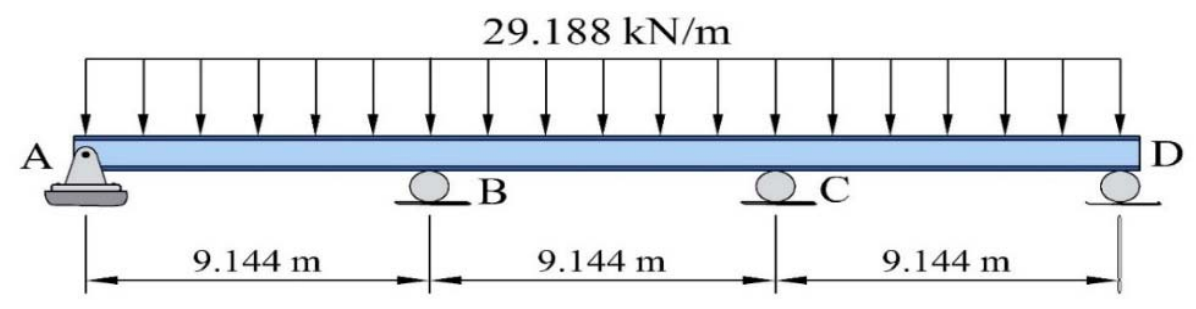

Fig.6. The beam in example 3.

In this example, the combined effects due to both the external loading and the support settlements are investigated in order to show the application of slope-deflection equations under this situation. It can be clearly noticed from Table 4 that the effects of the support settlements are considered by substituting the values of $\psi$ in the original slope-deflection equations, while the support settlements are considered as fixed end moments added to the fixed end moments due to external loading in the reduced slope-deflection equations.

It can be observed that the values of the fixed end moments are not identical for both equations, but the analysis results are identical, because the difference in fixed end moments are zeroed due to substituting the values of the rotations $\psi$ in the original equations.

It should be noted that the analyst may make a mistake when using the original equations (in support settlement cases) because of the confusion by adding the effect of support settlement twice (firstly in $\psi$ term and secondly in FEM term). The formulas of the fixed end moments due to the support settlements, which are used in the moment distribution method and those due to external loading in FEM Tables in the textbooks and references of the "structural analysis" are widely available and can easily be confused. This confusion does not occur when using the proposed reduced equations because the term of $\psi$ is cancelled in these equations.

Also, it is important to focus on a significant point relevant to dealing with the fixed end moments when using both the original and the reduced equations of the slope-deflection method; that is, in the analysis by using the original equations, the values of the fixed end moments are obtained from the effects of the externally applied loads only, while in using the reduced equations the values of the fixed end moments are obtained from the effects of the externally applied loads and/or the effects of the relative vertical displacements (support settlements).

From the above three examples, it can be observed that the reduced equations have a smaller number of variables compared with the original equations (equations without $\psi$ term) which leads to fewer computations when using the proposed reduced equations in the case of $\psi=0$. On the other hand, when $\psi \neq 0$, the computational efforts are similar for both the reduced and the original equations because in reduced equations we have to calculate an additional fixed end moment due to support settlement but without calculating a value of $\psi$, while in the original equations we have to calculate the value of $\psi$ without calculating an additional fixed end moment. In overall, it can be considered that the reduced equations are more convenient in use because they have shorter forms and fewer computations in the case of $\psi=0$, which is the common case in practice, while in the rare case of $\psi \neq 0$, both the original and the reduced equations have approximately the same computational efforts but the reduced equations still have shorter forms (equations without $\psi$ term).

\section{Conclusions}

The conclusions of this research can be summarized as follows:

1. It is possible to reduce the equations of the slope-deflection method by cancelling the term of the member rotation $\psi$ and considering its effect in the term of the fixed end moment.

2. The reduced equations of the slope-deflection method are: 


$$
\begin{aligned}
& M_{N F}=2 E k\left(2 \theta_{N}+\theta_{F}\right)+F E M_{N F} \text { (basic equation), } \\
& M_{F N}=2 E k\left(2 \theta_{F}+\theta_{N}\right)+F E M_{F N} \text { (basic equation), } \\
& M_{N F}=3 E k \theta_{N}+F E M_{N F} \text { (modified equation). }
\end{aligned}
$$

The term FEM in the reduced equations represents the fixed end moment caused by the external loads and/or the support settlements, while in the original equations it represents the fixed end moment caused by the external loads only. All other definitions of the parameters in the above reduced equations are the same as those of the original slope-deflection equations.

3. When there are no relative displacements at the joints of the members (when $\psi=0$ ), the use of the reduced equations is more convenient and requires fewer computational efforts compared with using the original equations, while the computations are approximately the same when the joints of the members have relative displacements $(\psi \neq 0)$, which is a rare case in practice.

4. It is preferred to use the reduced equations of the slope-deflection method presented in this study instead of the original slope-deflection equations because the reduced equations give completely the same results with simpler forms and mostly easier computations.

\section{Nomenclature}

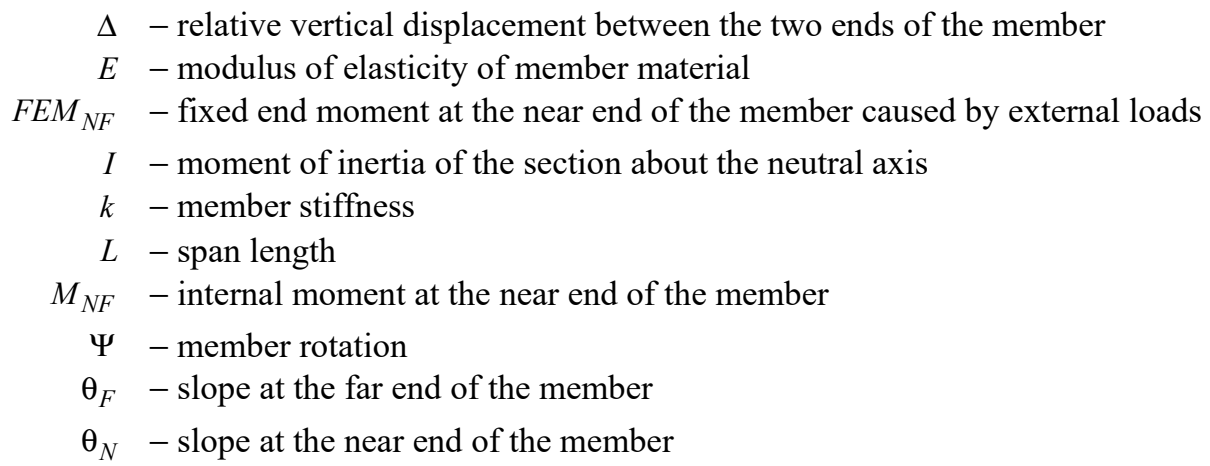

\section{References}

[1] Ghali A., Neville A.M. and Brown T.G. (2017): Structural Analysis: A Unified Classical and Matrix Approach.Seventh edition, Boca Raton, FL: Taylor and Francis Group.

[2] Hibbeler R.C. (2015): Structural Analysis.- Ninth edition, New Jersey, Pearson Education Inc.

[3] Kassimali A. (2020): Structural Analysis.- Sixth edition, Boston, MA, Cengage Learning Inc.

[4] Mau S.T. (2012): Introduction to Structural: Displacement and Force Methods. - Boca Raton, FL, Taylor and Francis Group.

[5] McCormac J.C. (2007): Structural Analysis using Classical and Matrix Methods.- Fourth edition, John Wiley and Sons Inc.

[6] Spencer W.J. (1998): Fundamental Structural Analysis.- Springer-Verlag New York Inc.

[7] Derucher K., Putcha C. and Kim U. (2013): Indeterminate Structural Analysis.- Lewiston, New York, The Edwin Mellen Press Ltd.

[8] KhalafAllah S. (2018): Structural Analysis Statically Indeterminate Structures.- ISTE Ltd.

[9] Punma P.C., Jain A. and Jain A. (2004): Theory of Structures.- Twelfth edition, New Delhi, Laxmi Publications (P) Ltd.

[10] Yoshida S. (1961): Analysis of rigid frames in space by applying slope-deflection formulas.- Journal of the Faculty of Engineering, no.12, pp.35-112. 
[11] Backer H.D., Outtier A. and Bogaert P.V. (2008): Analytical calculation of internal forces in orthotropic plated bridge decks based on the slope-deflection method.- Journal of Constructional Steel Research, vol. 64, No.12, pp.1530-1539.

[12] Aristizabal-Ochoa J. D. (2009): Stability and Second-Order Analysis of Timoshenko Beam-Column Structures with Semi-Rigid Connections: Slope-Deflection Method.- DYNA, Vol.76, No.159, pp.7-21.

[13] Riahi H. T., Barjoui A. S., Bazazzadeh S. and Etezady S. M. A. (2012): Buckling analysis of non-prismatic columns using slope-deflection method.- Proceedings of $15^{\text {th }}$ World Conference on Earthquake Engineering, Lisbon, Portugal, Vol.36, pp.28700-28709.

[14] Husain M. A. (2015): New Modification for slope-deflection equation in structural analysis.- International Journal of Engineering and Technical Research, Vol.3, Issue 7, pp.387-390.

[15] Ranzi G. and Gilbert R. I. (2015): Structural Analysis Principles Methods and Modelling.- Boca Raton, FL, Taylor and Francis Group.

Received: July 26, 2021

Revised: October 25, 2021 